\title{
Effect of the Fund Policy in a Remanufacturing System considering Ecodesign and Responsibility Transfer
}

\author{
Shan Wang, Xiang-Yun Chang $\mathbb{D}^{D}$, and Xin Huang \\ Department of Management Science and Engineering, East China University of Science and Technology, Shanghai 200237, China \\ Correspondence should be addressed to Xiang-Yun Chang; xychang@ecust.edu.cn
}

Received 3 May 2021; Revised 17 August 2021; Accepted 18 August 2021; Published 8 September 2021

Academic Editor: Jinyu Chen

Copyright ( $\odot 2021$ Shan Wang et al. This is an open access article distributed under the Creative Commons Attribution License, which permits unrestricted use, distribution, and reproduction in any medium, provided the original work is properly cited.

\begin{abstract}
This paper aims to evaluate the effectiveness of the fund policy on ecodesign and manufacturing/remanufacturing activities and the effectiveness of the manufacturer's ecodesign responsibility transfer strategy. It considers a manufacturing and remanufacturing system composed of a single manufacturer and a single remanufacturer performing under relevant fund policy. The fund policy is innovatively designed by considering three dimensions: tax, reduction, and subsidy. Based on mathematical models and comparative analysis, the principal results show the following: (1) the impact scope of either the tax or the reduction dimension of the fund policy is larger than that of subsidy. The subsidy for encouraging remanufacturing is effective only when the remanufacturer uses some of the collected returns for remanufacturing. (2) The impact direction of tax, reduction, or subsidy is complicated, changing when the remanufacturer uses some of the collected returns for remanufacturing. (3) The responsibility transfer behavior of the manufacturer does not change the impact scope of the fund policy, but changes its impact strength and impact path. The impact of the responsibility transfer strategy on enterprises' decision-making varies with different remanufacturing scenarios.
\end{abstract}

\section{Introduction}

A range of Extended Producer Responsibility (EPR) programs around the world have been developed for managing waste. EPR is an environmental protection strategy to enforce take-back, recycling, and final disposal efforts by manufacturers [1].

Fund policy is one typical form of EPR regulation implementation, which is prevalent in Mainland China and Taiwan [2-4]. For example, Taiwan initialized the Recycling Fund Management Board of the Environmental Protection Administration (EPA) in 1998, and the Ministry of Finance in Mainland China created the E-waste Processing Fund Collection and the Subsidy Management Approach in 2012.

The fund policy can be considered a synthesis of environmental taxes and subsidies. A waste tax is levied on manufacturers per unit product sold to consumers. Proceeds are then channeled into a recycling management fund and used to promote recycling incentives. At the recycling and reuse stage, the disassembling enterprises or recyclers are subsidized according to the actual amount of waste they process $[3,5]$.

Fund policy and other forms of EPR regulation across the world are similar in purpose, which is twofold. One task is to promote product ecodesign at the product development stage. The other task is to promote the recycling rate or recycling quantities at the recycling stage $[6,7]$. The former focuses on resource consumption reduction and waste prevention, while the latter focuses on resource reuse and recycling.

Ecodesign is defined as "the integration of environmental aspects into product design and development with the aim of reducing adverse environmental impacts throughout the whole product's life cycle" [8]. In fact, product ecodesign has an important impact on recycling and environmental protection. If producers adopt recycle and reuse-oriented ecodesign at the product development stage, the recycle frequency of waste products can be increased and pollution levels throughout the life cycle can be reduced. Many enterprises, such as Xerox and Kodak, take 
remanufacturing into consideration when they design their products [9].

Regardless of the fact that adoption of ecodesign strategies in product development can offer several advantages in industry, ecodesign is actually an environmental responsibility; however, performing ecodesign often raises a manufacturer's operating costs. At the same time, dealers or retailers often benefit from the manufacturer's ecodesign. It is unfair for a manufacturer to solely bear the ecodesign responsibilities. That is why manufacturers are not as supportive of ecodesign as expected [5] and often adopt responsibility transfer strategies to share their environmental responsibilities with other actors in the supply chain [10]. As such, how relative responsibilities are shared among supply chain members becomes an intriguing issue $[10,11]$.

Remanufacturing is generally perceived as an environmentally friendly end-of-use management option for many companies [12]. Companies can reduce production costs by extracting core components from used products instead of using new raw materials [13]. For example, Caterpillar, HP, and Xerox have saved $30-70 \%$ production costs from their recycling and remanufacturing activities of end-of-life products. In 2015, Apple signed an agreement with Foxconn in which the latter acquired proprietary rights to remanufacture the end-of-life iPhone mobile phones and remarket them in China [14]. In general, remanufactured products have similar valuations to new products, and they are competitive substitutes for each other in the market.

Then, for a manufacturing-remanufacturing competition system considering ecodesign and its responsibility transfer strategy under the constraints of fund policy, the following questions are worth studying:

(1) How will the fund policy affect the ecodesign and production decisions of a manufacturer, and how will it affect the remanufacturing decisions of a remanufacturer?

(2) When a manufacturer adopts an ecodesign responsibility transfer strategy to transfer his own ecodesign responsibilities to other members in a supply chain, how will the impact of fund policy change? And how will the decisions of the manufacturer and remanufacturer change?

This paper will try to answer these questions by using game theory. The paper considers a manufacturing-remanufacturing competition system under the constraints of fund policy. A regulator designs the fund policy, which mainly consists of three dimensions-tax, reduction, and subsidy - that influence ecodesign efforts and manufacturing/remanufacturing decisions. A manufacturer produces a key component and a new product in the market. The key component cannot be remanufactured and can only be sold by the manufacturer at a buyer-specific wholesale price or through a responsibility transfer strategy. A remanufacturer recycles old parts and purchases key components from the manufacturer for remanufacturing. The new product and remanufactured product are competitive substitutes in the market.
The aim of this paper is to investigate the effect of fund policy on ecodesign and manufacturing/remanufacturing activities and to investigate the effect of the manufacturer's ecodesign responsibility transfer strategy. The main contributions of this research are as follows.

(1) A new fund reduction policy is proposed as an alternative scheme, and the fund policy is refined to consider three dimensions: tax, reduction, and subsidy. The reduction dimension is used to provide better incentives for manufacturers to carry out ecodesign, which was seldom considered in the previous research, but which has extended the existing research that mainly considers tax and subsidy.

(2) Ecodesign (waste prevention measure) and remanufacturing (waste end-treatment measure) will be considered at the same time. This means that waste prevention and waste end-treatment are both considered in one system, which is innovative.

(3) The paper considers a key component that cannot be remanufactured in the manufacturing-remanufacturing competition system, as well as ecodesign responsibility transfer strategy, which makes this research more sophisticated.

The remainder of this paper is organized as follows. Section 2 reviews the relevant literature. Section 3 presents the basic model (B-model) and analyzes the obtained perfect equilibria. Section 4 considers ecodesign responsibility transfer and presents the T-model. Section 5 comparatively analyzes the system equilibrium of the two models. Section 6 concludes the paper.

\section{Literature Review}

This research is closely related to four research directions: EPR regulation, fund policy, ecodesign, and responsibility transfer. In this section, the relevant studies are reviewed to provide an overview of previous studies and bring forward an innovative perception of the paper.

2.1. EPR Regulation. Mainly aimed at the disposal responsibility of waste products, EPR requires producers to undertake the responsibility of recycling or disposing of products after use. This means that the producer bears the actual responsibility for product recovery and disposal, or the responsibility for product recovery and disposal costs; that is, the producer can transfer his responsibility under the EPR to a third party using a paid transfer strategy.

The implementation of EPR is flexible and diverse all around the world. Generally speaking, EPR legislation is implemented in two typical ways: M-operated systems and G-operated systems. M-operated systems (manufactureroperated) indicate that manufacturers operate their own recycling network (self-operated or outsourced) to manage and recycle their products' waste. The government assigns recycling tasks (minimum recovery and recycling) to the 
manufacturer. For example, the WEEE Directive of the European Union adopts M-operated systems. As for G-operated systems (government-operated), the government is responsible for recycling waste products, and the manufacturer pays the government a certain fee for the process. For example, G-operated systems are adopted in the Chinese mainland and Taiwan region for the management of waste household appliances and electronic products. However, the fund system still needs to be further standardized. There are some problems, such as incomplete extension of responsibility, insufficient correlation between economic responsibility and ecodesign for producers, and lack of an incentive system for multiagent responsibility. Kautto and Melanen [15] pointed out that since the EU WEEE Directive did not have any contribution to waste prevention, the scope of policy should be drastically shifted from waste management to society's overall cycles of materials and products. Wang et al. [16] systematically analyzed the physical and financial operating mechanisms of EPR systems in Japan, Germany, Switzerland, and China and pointed out that although the operation mechanism of EPR systems varied greatly in different countries, there were some common problems. Li et al. [17] used the newsvendor model and numerical simulation method and concluded that the EPR coefficient policy was an appropriate and effective approach to promote the EPR practice of the Chinese government.

2.2. Fund Policy. Taking these considerations into effect, scholars have carried out varied research on fund policy. Pazoki et al. [18] discussed how to set the values of subsidies and penalties in several environmental regulations to minimize the environmental impact of production or to maximize product recovery. Cao et al. [19] analyzed the effect of environmental regulations and financial measures stipulated by the government. Guo et al. [20] used the system dynamic method to analyze how China's "WEEE processing fund" policy influences the economic and environmental conditions of participants in the WEEE management system. Chang et al. [21] found that the joint tax-subsidy mechanism can motivate the manufacturer to pursue ecoinnovation and to incorporate recycling considerations into its production and ecoinnovation decisions. Chen et al. [22] investigated the behavior of supply-chain members in green supply chain management under the reward-penalty mechanism and found that the return rate and green effort can be improved by the reward-penalty mechanism. Hong and Guo [23] found that the policy balanced the interests of manufacturers, importers, sellers, and recyclers by choosing an optimal selling quantity in the market and optimal reward money for customers bringing end-of-life products to recyclers. Pazoki and Samarghandi [24] found that a regulated manufacturer practiced remanufacturing for a costly ecodesign. Wang et al. [25] presented a tripartite evolutionary game model consisting of the government, the recycler, and the consumer, determined the payoff matrices of the system, and calculated the replicator dynamic equation of each participant. The results showed that the government should play a leading role in the development of the e-waste recycling industry. Zhang et al. [26] found that government tax and subsidy policies could not always improve enterprises' remanufacturing behavior. Zhang et al. [27] researched optimal pricing and remanufacturing modes in a closed-loop supply chain of WEEE under government fund policy. Liu et al. [28] introduced a dual regulation regime characterized by the deposit-refund policy and a minimal collection rate of used products. They found that regulating the minimal collection rate was beneficial to the environment and helped to reduce the deposit-refund policy deficit under certain conditions.

It can be seen that scholars mainly pay attention to the recycling fund policy in terms of fund collection, subsidies, and fund management. However, the current research on policy design seldom considers the ecodesign behavior of the manufacturer and waste prevention at the source.

2.3. Ecodesign. In fact, product ecodesign has an important impact on recycling and environmental protection. If producers adopt recyclable and reuse-oriented ecodesign in the product design stage, the recycling frequency of waste products can be improved and life cycle pollution can be reduced. Örsdemir et al. [12] believed that about two-thirds of the remanufacturability of recycled products depended on the remanufacturing design at the initial stage of product design. Calcotta and Walls [29] examined the impacts of policies to encourage efficient product design and recycling and found that optimal outcomes could be attained by combining a "deposit-refund" policy. Zhu and $\mathrm{He}$ [30] indicated that supply chain price competition at the retailer level might positively influence equilibrium greenness, while product greenness competition reduces equilibrium greenness. Zand et al. [31] found that the green level of the products positively contributed to the amount of collected used products and increased the retailer's profit. Zheng et al. [32] put forward a theoretical model to discuss the influence of competitive strategy on Design for Environment (DFE). DFE can help reduce the impact of products on the environment, but high levels of DFE may harm the environment by substantially increasing total sales.

Therefore, most of the current quantitative modeling research on ecodesign simply takes ecodesign as a decision variable, which is far from detailed and in-depth.

2.4. Responsibility Transfer. Ecodesign responsibility is actually an environmental responsibility. Performing environmental responsibility often brings relevant operating costs to enterprises. Therefore, manufacturers often adopt different ecological design strategies according to cost, income, market competition, and other factors. Subramanian et al. [33] found that the competition between manufacturing and remanufacturing products would change the ecodesign strategy. Hong and Guo [23] studied several cooperation contracts within a green product supply chain and investigated their environmental performance. Mathiyazhagan et al. [34] found that OEMs could complete green supply chain management requirements by merging 
and splitting responsibilities. Cheng et al. [10] found that when the OEM and retailer worked together, the responsibility transfer factor did not affect their dual performance. Governments and retailers should consider ecological and environmental protection targets and profits in the OEM strategy.

To sum up, the existing literature has provided an important theoretical basis for fund policy. However, many of these studies pay more attention to recycling and endtreatment of waste, but less attention to ecodesign of the production stage in a closed-loop supply chain. It is necessary to explore new incentive methods and new fund policy operation modes considering both ecodesign (waste prevention measure) and remanufacturing (waste endtreatment measure), as well as ecodesign responsibility transfer strategies.

\section{Basic Model and Analysis}

3.1. Model and Solution. This paper considers a manufacturing-remanufacturing competition system under fund policy. To promote ecodesign and recycling, the government designs the fund policy considering three dimensions, namely, tax, reduction, and subsidy, which are assumed to be exogenous. The manufacturer produces products, sells them to consumers in the market, and produces a key component that cannot be remanufactured. The remanufacturer recycles waste products and purchases the key component from the manufacturer for remanufacturing. The new product and the remanufactured product are competitive substitutes in the market. The structure of the system is depicted in Figure 1, and a summary of notations can be found in Table 1.

Next, we will describe the assumptions and basic model in detail. We assume the manufacturer sets a buyer-specific wholesale price of the key component tailored to the remanufacturer in the basic model (B-model).

3.1.1. The Regulator. The regulator designs the fund policy, which mainly includes three dimensions: tax, reduction, and subsidy. The regulator levies the waste $\operatorname{tax} T_{0}$ on the manufacturer per product sold to consumers (tax mechanism) and issues quota subsidies $s$ to qualified remanufacturers for waste recycling and dismantling (subsidy mechanism). At the same time, in order to encourage the manufacturer to conduct ecodesign, tax reduction is carried out based on ecodesign effort. The unit tax reduction is $\sigma e$ (reduction mechanism).

3.1.2. The Manufacturer. The manufacturer $(m)$ strategically decides on product ecodesign effort $e$ and fulfills its ecodesign responsibility under the constraints of fund policy. Meanwhile, the manufacturer needs to decide on the production quantity of the new product $q_{n}$. It costs the manufacturer $(1 / 2) \mathrm{d} e^{2}$ to exert ecodesign effort $e$; this formula $(1 / 2) \mathrm{d} e^{2}$ is widely used in other literatures, such as Zhu and He [30] and Chen and Ulya [35]. New products and remanufactured products are competitive substitutes in the market. Given the quantities of new and remanufactured products $q_{n}, q_{r}$, the market-clearing prices for new and remanufactured products are $p_{n}=1-q_{n}-\delta q_{r}$ and $p_{r}=\delta\left(1-q_{n}-q_{r}\right)$, respectively. These functions are widely used in the literature for closed-loop supply chain management; see Zheng et al. [32]; Wu and Zhou [36]; and Jacobs and Subramanian [11]. The manufacturer has the technology to produce a key component that cannot be remanufactured. Referring to Chen et al. [22], it is assumed that the manufacturer incurs two costs when producing a new product: the unit cost of the key component $m$ and the unit production cost of the new product $c_{n}$.

3.1.3. The Remanufacturer. The remanufacturer $(r)$ determines remanufacturing quantity $q_{r}$ under the constraint of fund policy. Assume that $q_{r} \leq \tau q_{n}$ and all remanufactured products can be sold. The unit remanufacturing cost is $c_{r}$. The ecodesign effort of the manufacturer (such as modular design to make disassembly easier) benefits the remanufacturer, and the reduction of unit remanufacturing cost is $\alpha e$. The remanufacturer needs to purchase the key component from the manufacturer at a buyer-specific wholesale price $w_{0}$ during the process of remanufacturing.

The manufacturer and remanufacturer pursue profit maximization, and the decision model is

$$
\left\{\begin{array}{l}
\operatorname{Max} \pi_{\left(e, q_{n}\right)}^{\pi_{m}}=\underbrace{\left(p_{n}-c_{n}-m\right) q_{n}}_{\text {Sales revenue of new product }}-\underbrace{\frac{d}{2} e^{2}}_{\text {Eco-design cost }}+\underbrace{\left(w_{0}-m\right) q_{r}}_{\begin{array}{c}
\text { Sales revenue of } \\
\text { key compoment }
\end{array}}-\underbrace{\left(T_{0}-\sigma e\right) q_{n}}_{\text {Waste tax }}, \\
\operatorname{Max} \pi_{r}^{\left(q_{r}\right)}=\underbrace{\left[p_{r}-\left(c_{r}-\alpha e\right)-w_{0}\right] q_{r}}_{\text {Sales revenue of remanufacturing product }}+\underbrace{s q_{r}}_{\text {Government subsidy }}, \\
0 \leq q_{r} \leq \tau q_{n} .
\end{array}\right.
$$




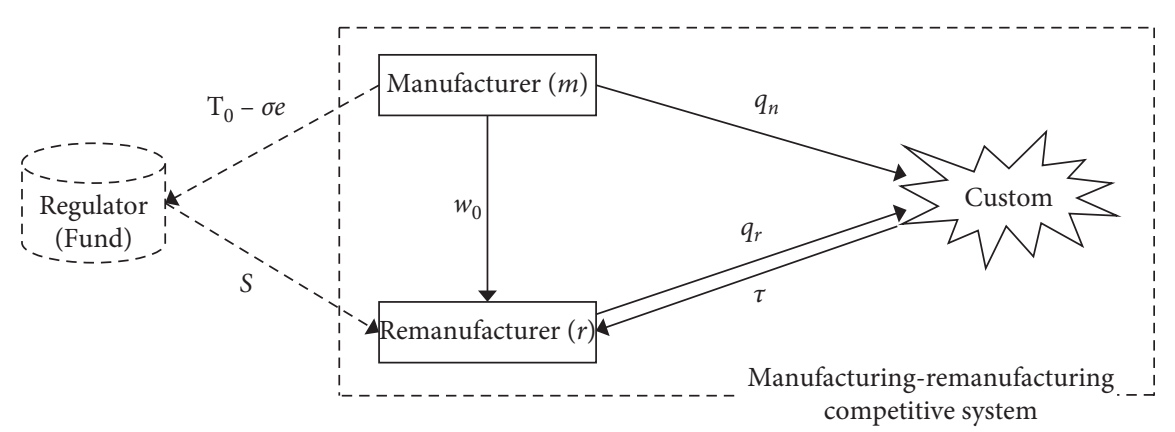

FIgURE 1: A manufacturing-remanufacturing competitive system with the fund policy.

TABLE 1: Notations.

\begin{tabular}{|c|c|c|}
\hline & & Descriptions \\
\hline \multirow{13}{*}{ Parameters } & $\begin{array}{c}T_{0} \\
\sigma\end{array}$ & $\begin{array}{l}\text { Waste tax per unit product sold to consumers imposed by the regulator on the manufacturer } \\
\text { Tax reduction coefficient per unit product given by the government for encouraging the manufacture's ecodesign } \\
\text { activity, } \sigma \in(0,1)\end{array}$ \\
\hline & $s$ & Unit subsidy per unit remanufactured product received from the regulator \\
\hline & $d$ & The sensitivity of production cost to the ecodesign \\
\hline & $\delta$ & Consumer's willingness to pay for the remanufactured product $\delta \in(0,1)$ \\
\hline & $c_{n}$ & Unit production cost of a new product \\
\hline & $c_{r}$ & Unit production cost of a remanufactured product \\
\hline & $m$ & Unit cost of a key component \\
\hline & $\Delta$ & The unit cost savings of production through remanufacturing, $\Delta=c_{n}-c_{r}$ \\
\hline & $\alpha$ & Unit remanufacturing cost reduction coefficient that the manufacturer's ecodesign brings to the remanufacturer \\
\hline & $w_{0}$ & A buyer-specific wholesale price of the key component to the remanufacturer \\
\hline & $p_{n}$ & Unit sale price of a new product \\
\hline & $p_{r}$ & Unit sale price of a remanufactured product \\
\hline & $\tau$ & Recycling rate of used products $(0<\tau \leq 1)$ \\
\hline \multirow{3}{*}{$\begin{array}{l}\text { Decision } \\
\text { variables }\end{array}$} & $q_{n}$ & Sales quantity of new products \\
\hline & $q_{r}$ & Sales quantity of remanufactured products \\
\hline & $e$ & The manufacturer's ecodesign effort \\
\hline
\end{tabular}

Manufacturer and remanufacturer's decision goal is to maximize profit. The order of game is as follows: in the first stage, the manufacturer decides product ecodesign effort $e$. In the second stage, the remanufacturer decides on the remanufactured product quantity $q_{r}$ according to the ecodesign effort of the manufacturer. At the same time, the manufacturer also decides on new product quantity $q_{n}$. This game order has been used in the literatures, such as Zheng et al. [32] and Reimann et al. [37], in order to make all decisions within a period of stability and not disperse the time-cycle effect when studying the interactions within the manufacturing-remanufacturing supply chain. Assuming that the manufacturer and the remanufacturer make the same decision at each stage in the steady-state equilibrium, the production quantity decision made by the manufacturer and the remanufacturer in the second stage can be regarded as simultaneous.

We solve the two-stage game described above by backward induction. First, $q_{n}, q_{r}$ are obtained and substituted back to $\pi_{m}, \pi_{n}$, and then $e$ can be got. Proposition 1 presents the optimal equilibrium strategies of the manufacturer and remanufacturer.

Next, for convenience in writing, the $B A$ scenario represents the case when the remanufacturer uses all the collected returns for remanufacturing in the B-model, and the
$B S$ scenario represents the case when the remanufacturer uses some of the collected returns for remanufacturing in the B-model.

Proposition 1. In the manufacturing-remanufacturing competition system under the constraints of fund policy, the optimal equilibrium strategies of the manufacturer and remanufacturer can be seen in Table 2, where $K=1-c_{n}-m$; $d(2+\delta \tau)^{2}-2 \sigma^{2}>0 ;$ andd $(4-\delta)^{2}-2(\alpha-2 \sigma)^{2}>0$.

Proof. All proofs are relegated to Appendix.

3.2. Analysis. As described in Section 3.1, the fund policy we researched in this paper includes three dimensions: tax, reduction, and subsidy, which are, respectively, represented by the parameters $T_{0}, \sigma, s$ in the B-model. The impacts of the three parameters on ecodesign decision and manufacturing/ remanufacturing activities will be analyzed next.

3.2.1. Impact Scope of the Fund Policy. By observing the relationship between the optimal solution $e^{i^{*}}, q_{n}^{i^{*}}, q_{r}^{i^{*}}(i=B A, B S)$ and the fund policy factors $T_{0}, \sigma, s$ in Table 2, Conclusion 1 can be obtained. 


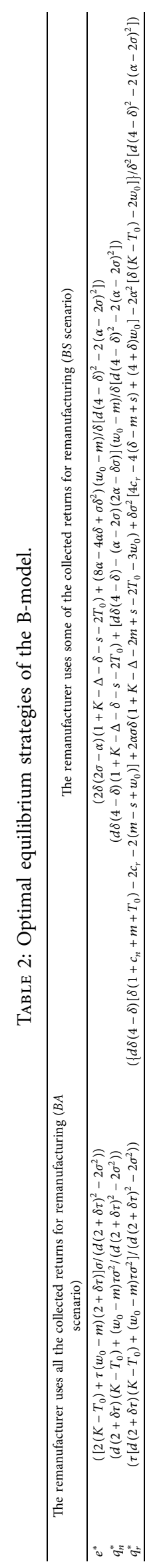


Conclusion 1. The tax factor $T_{0}$ and the reduction factor $\sigma$ affect all decisions $e^{i^{*}}, q_{n}^{i^{*}}, q_{r}^{i^{*}}(i=B A, B S)$ both in the $B A$ scenario and in the $B S$ scenario, while the subsidy factor $s$ only affects the decisions $e_{n}^{B S^{*}}, q_{n}^{B S^{*}}, q_{r}^{B S^{*}}$ in $B S$ scenario.

Therefore, the impact scope of fund policy is larger in the $B S$ scenario than in the $B A$ scenario.

(a) In the $B A$ scenario, the market environment is extremely favorable for remanufacturing, and the subsidy policy for encouraging recycling and remanufacturing is ineffective. Therefore, once the remanufacturer decides on using all the collected returns for remanufacturing based on market conditions, the government should focus on the policy factors for the manufacturer rather than the remanufacturer, so as to bolster the manufacturer's focus on ecodesign and waste prevention measures at the production stage.

(b) In the BS scenario, the factors of tax, reduction, and subsidy affect both the manufacturer's and remanufacturer's decisions. So, the government should not only consider the impact of one single policy factor, but should consider the impact of three factors-tax, reduction, and subsidy - as a whole when designing the fund policy in the $B S$ scenario.

3.2.2. Impacts of Fund Policy Factors on Decision-Making. The relationships between the optimal solution in Table 2 and the first-order partial derivatives $T_{0}, \sigma, s$ are shown in Proposition 2.

Proposition 2. For the manufacturing-remanufacturing competition system under the constraints of fund policy, the relationship between optimal equilibrium strategies and the first-order partial derivatives, $T_{0}, \sigma, s$, in the $B A$ and $B S$ scenarios is shown in line 1 and line 2 of Table 3, respectively.

From Table 3, we observe the following: (a) In the $B A$ scenario, $e^{B A^{*}}, q_{n}^{B A^{*}}, q_{r}^{B A^{*}}$ all decrease with respect to $T_{0}$. The effect of the reduction factor $\sigma$ is opposite to that of the tax factor $T_{0}$, and the subsidy factor, $s$, does not affect the decisions of the manufacturer and remanufacturer. (b) In the $B S$ scenario, $T_{0}, \sigma, s$ have a complex impact on decisions of the manufacturer and remanufacturer. Take $T_{0}$ for example. It can promote ecodesign efforts in some cases, while it will weaken ecodesign efforts in other cases. The key is the relationship between $\alpha$ and $\sigma$; the turning point of policy impact is $\sigma=(\alpha / 2)$.

In order to observe the complex impact of $T_{0}, \sigma, s$ on the optimal decisions $e^{B S^{*}}, q_{n}^{B S^{*}}, q_{r}^{B S^{*}}$ in $B S$ scenario, we plot Figure 2 where $\alpha=0.6, \sigma=0.3$. Given the impact of $T_{0}, s$ that has been shown in Table 3 , the focus here is on the complex impact of $\sigma$ on the manufacturer's and remanufacturer's decisions.
From Figure 2, we can observe the following:

(i) When subsidy $s$ is constant and tax $T_{0}$ is low, as $\sigma$ increases, the ecodesign effort $e^{B S^{*}}$ is higher (Figure 2(a)), $q_{n}^{B S^{*}}$ increases (Figure 2(b)), and $q_{r}^{B S^{*}}$ first decreases and then increases (Figure 2(c)). However, the effect of $\sigma$ is changed when $s$ is constant and $T_{0}$ is high (Figures 2(a)-2(c)).

(ii) When $T_{0}$ is constant and subsidy $s$ is low, as $\sigma$ increases, the ecodesign effort $e$ first decreases and then increases (Figure 2(d)), $q_{n}^{B S^{*}}$ increases (Figure 2(e)), $q_{r}^{B S^{*}}$ first decreases and then increases (Figure 2(f)).

From the perspective of fund policy design by the government, we can put forward managerial implications as follows:

(a) In the $B A$ scenario, the focus of fund policy design by the government should be the tax dimension and the reduction dimension. By reducing the tax and increasing tax reduction, the manufacturer can be encouraged to improve ecodesign efforts and strengthen the prevention of waste management at the production stage.

(b) In the $B S$ scenario, the impact mechanism of the tax, reduction, and subsidy dimensions of fund policy is complex and changeable, so the government should integrate design of the three dimensions-_tax, reduction, and subsidy-_to create a balanced guidance of fund policy on ecodesign and remanufacturing behavior. In particular, the reduction dimension of fund policy must be set carefully in the $B S$ scenario; otherwise, it will not only weaken ecodesign and remanufacturing at the supply chain level, but will also lead to negative impacts from the tax and subsidy dimensions of fund policy on ecodesign and remanufacturing at the policy level.

\section{Impact of Ecodesign Responsibility Transfer}

Based on the B-model in Section 3, we will introduce the manufacturer's ecodesign responsibility transfer strategy to explore the impact of ecodesign responsibility transfer strategy in this chapter.

4.1. Modeling and Solution. Referring to the research of Cheng et al. [10], the manufacturer's ecodesign responsibility transfer is reflected in the wholesale price of the key component, which is set as $\left(w_{0}+h_{e} e\right)$ instead of the buyerspecific wholesale price in the B-model in Section 3, where $h_{e} \in[0,1]$ is the transfer coefficient; the greater the value is, the more the ecodesign responsibility is transferred.

The decision model of the ecodesign responsibility transfer strategy (T-model) is 
TABLE 3: The relationship between optimal equilibrium strategies and $T_{0}, \sigma$, and $s$.

\begin{tabular}{lccccccccc}
\hline & $\left(\partial e^{*} / \partial T_{0}\right)$ & $\left(\partial q_{n}^{*} / \partial T_{0}\right)$ & $\left(\partial q_{r}^{*} / \partial T_{0}\right)$ & $\left(\partial e^{*} / \partial \sigma\right)$ & $\left(\partial q_{n}^{*} / \partial \sigma\right)$ & $\left(\partial q_{r}^{*} / \partial \sigma\right)$ & $\left(\partial e^{*} / \partial s\right)$ & $\left(\partial q_{n}^{*} / \partial s\right)$ & $\left(\partial q_{r}^{*} / \partial s\right)$ \\
\hline$B A$ scenario & - & - & - & + & + & + & $\times$ & $\times$ & $\times$ \\
$B S$ scenario $(\sigma<\alpha / 2 \mid \sigma>\alpha / 2)$ & $+/-$ & - & $+/ \sim$ & $\sim$ & $\sim$ & $\sim$ & $+/-$ & - & $+/ \sim$ \\
\hline
\end{tabular}

Note.,,$+- \sim$ and $\times$ indicate monotone increase, monotone decrease, and monotone uncertainty, respectively.

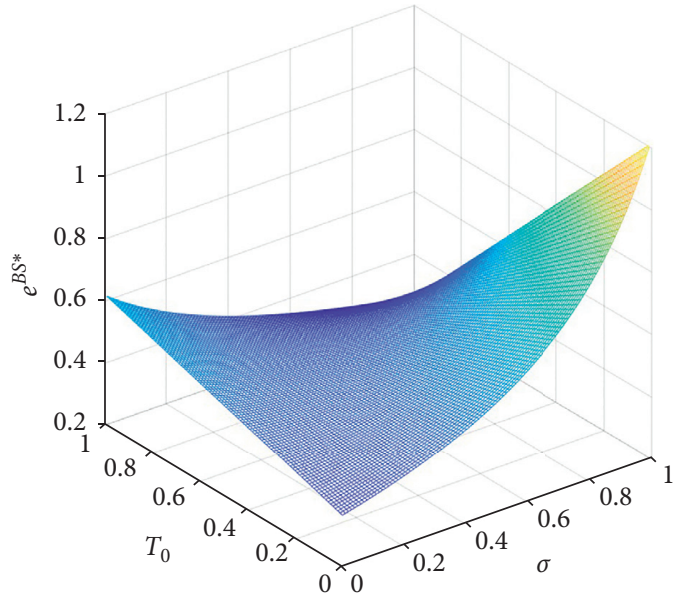

(a)

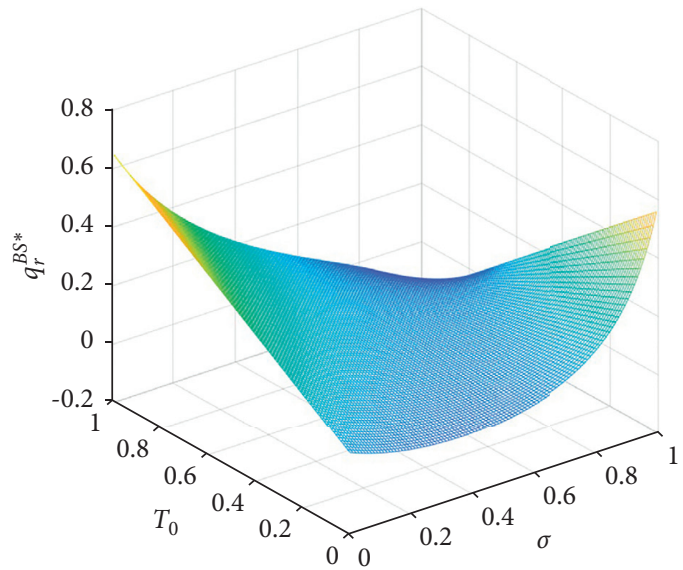

(c)

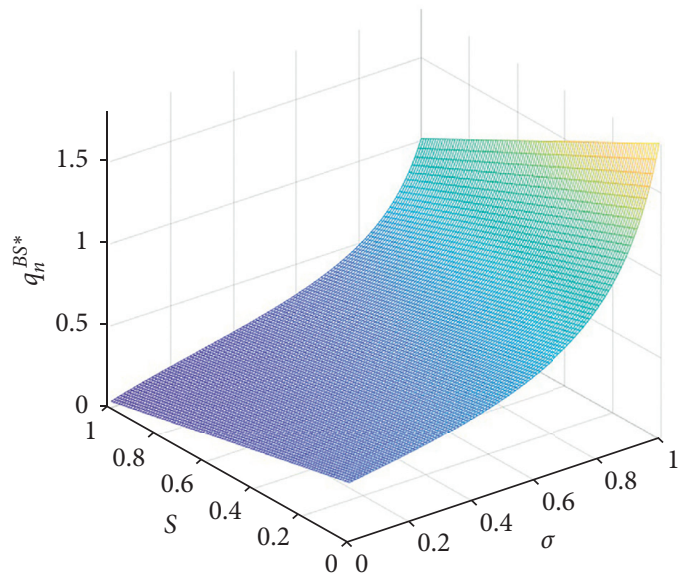

(e)

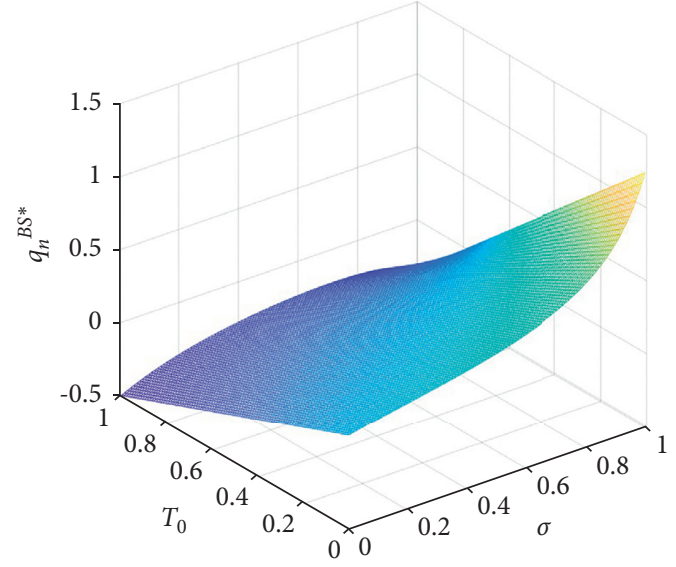

(b)

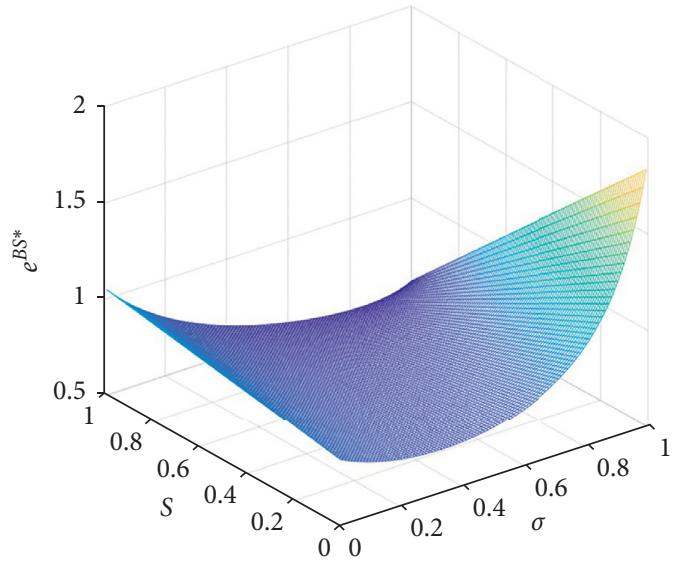

(d)

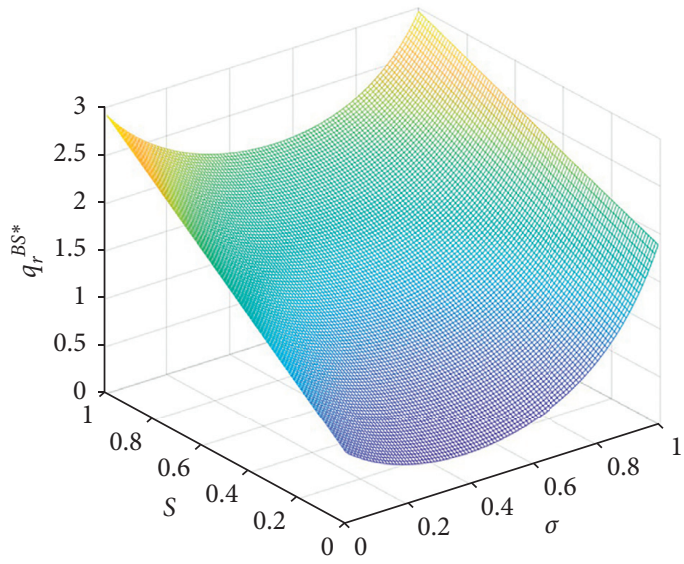

(f)

Figure 2: Effects of $T_{0}, \sigma$, and $s$ on $e^{B S^{*}}, q_{n}^{B S^{*}}$, and $q_{r}^{B S^{*}}$. (a) Effects of $T_{0}$ and $\sigma$ on $e^{B S^{*}}$. (b) Effects of $T_{0}$ and $\sigma$ on $q_{n}^{B S^{*}}$. (c) Effects of $T_{0}$ and $\sigma$ on $q_{r}^{B S^{*}}$. (d) Effects of $s$ and $\sigma$ on $e^{B S^{*}}$. (e) Effects of $s$ and $\sigma$ on $q_{n}^{B S^{*}}$. (f) Effects of $s$ and $\sigma$ on $q_{r}^{B S^{*}}$. 


$$
\left\{\begin{array}{l}
\operatorname{Max} \pi_{\left(e, q_{n}\right)}=\underbrace{\left(p_{n}-c_{n}-m\right) q_{n}}_{\text {Sales revenue of new product }}-\underbrace{\frac{d}{2} e^{2}}_{\text {Eco-design cost }}+\underbrace{\left(w_{0}+h_{e} e-m\right) q_{r}}_{\begin{array}{c}
\text { Sales revenue of } \\
\text { key compoment }
\end{array}}-\underbrace{\left(T_{0}-\sigma e\right) q_{n}}_{\text {Waste tax }}, \\
\operatorname{Max} \pi_{r}=\underbrace{\left[q_{r}-c_{r}-\left(w_{0}+h_{e} e\right)+\alpha e\right] q_{r}}_{\text {Sales revenue of remanufacturing product }}+\underbrace{s q_{r}}_{\text {Government subsidy }}, \\
0 \leq q_{r} \leq \tau q_{n} .
\end{array}\right.
$$

Next, the TA scenario represents the case where the remanufacturer uses all the collected returns for remanufacturing in the T-model, and the TS scenario represents the case where the remanufacturer uses some of the collected returns for remanufacturing in the T-model.

The manufacturer and remanufacturer pursue profit maximization, and the solution process is similar to Section
3.1. The detailed proof is omitted. The optimal solution is as follows:

(a) TA scenario: when the remanufacturer uses all the collected returns for remanufacturing:

$$
\begin{aligned}
& e^{T A^{*}}=\frac{\left[2\left(K-T_{0}\right)+\tau\left(w_{0}-m\right)(2+\delta \tau)\right] \sigma+h_{e} \tau(2+\delta \tau) K}{d(2+\delta \tau)^{2}-2 \sigma^{2}-2 \sigma h_{e} \tau(2+\delta \tau)}, \\
& q_{n}^{T A^{*}}=\frac{d(2+\delta \tau)\left(K-T_{0}\right)+\left(w_{0}-m\right) \tau \sigma^{2}-\tau \sigma h_{e}\left(K-T_{0}\right)}{d(2+\delta \tau)^{2}-2 \sigma^{2}-2 \sigma h_{e} \tau(2+\delta \tau)}, \\
& q_{r}^{T A^{*}}=\frac{\tau\left\{d(2+\delta \tau)\left(K-T_{0}\right)+\left(w_{0}-m\right) \tau \sigma^{2}-\tau \sigma h_{e}\left(K-T_{0}\right)\right\}}{d(2+\delta \tau)^{2}-2 \sigma^{2}-2 \sigma h_{e} \tau(2+\delta \tau)},
\end{aligned}
$$

where $d(2+\delta \tau)^{2}-2 \sigma^{2}-2 \sigma h_{e} \tau(2+\delta \tau)>0$.

(b) TS scenario: when the remanufacturer uses some of the collected returns for remanufacturing:

$$
\begin{aligned}
& 2 \delta(2 \sigma-\alpha)\left(1+K-\Delta-\delta-s-2 T_{0}\right)+(8 \alpha-4 \alpha \delta+\delta \sigma \delta)\left(w_{0}-m\right) \\
& e^{T S^{*}}= \frac{-h_{e}\left\{4 c_{r}(2-\delta)+\delta\left[\delta\left(3+c_{n}+m+T_{0}\right)+2\left(m+2 s-3 w_{0}\right)\right]-8\left(\delta+m+s-2 w_{0}\right)\right\}}{\delta\left[d(4-\delta)^{2}-2(\alpha-2 \sigma)^{2}\right]-2(8-3 \delta) h_{e}^{2}-2 \delta^{2} h_{e} \sigma+8 \alpha h_{e}(2-\delta)}, \\
&\left(\alpha-h_{e}\right)\left\{h_{e}\left[-2 c_{r}+c_{n}(8-\delta)+\delta\left(3-m-T_{0}\right)-2\left(4-3 m-s-4 T_{0}\right)\right]-2 a\left(w_{0}-m\right)\right\} \\
&+d \delta(4-\delta)\left(2+w_{0}-2 c_{n}+c_{r}-\delta-2 m-s-2 T_{0}\right) \\
&\left\{2 c_{r}(2-\delta) h_{e}+2 \delta^{2} h_{e}+4 \alpha m+4 h_{e}\left(2 w_{0}-m-s\right)-\alpha \delta\left(w_{0}-m\right)\right. \\
& q_{n}^{T S^{*}}=\left.+\delta h_{e}\left[2 c_{n}+m+2\left(-3+s+T_{0}\right)-w_{0}\right]-4 \alpha w_{0}\right\} \sigma-2 \delta\left(w_{0}-m\right) x g m^{2} \\
& \delta\left[d(4-\delta)^{2}-2(\alpha-2 \sigma)^{2}\right]-2(8-3 \delta) h_{e}^{2}-2 \delta^{2} h_{e} \sigma+8 \alpha h_{e}(2-\delta)
\end{aligned}
$$




$$
\begin{aligned}
& 8 c_{r} \mathrm{~d} \delta-4 \mathrm{~d} \delta^{2}-4 c_{n} \mathrm{~d} \delta^{2}-2 c_{r} \mathrm{~d} \delta^{2}+\mathrm{d} \delta^{3}+c_{n} \mathrm{~d} \delta^{3}+4 c_{r} h_{e}^{2}+4 c_{n} \delta h_{e}^{2}-4 d \delta^{2} m \\
&+\mathrm{d} \delta^{3} m+4 h_{e}^{2} m-4 \delta h_{e}^{2} m-8 \mathrm{~d} \delta s+2 \mathrm{~d} \delta^{2} s-4 h_{e}^{2} s-4 \mathrm{~d} \delta^{2} T_{0}+\mathrm{d} \delta^{3} T_{0}-4 \delta h_{e}^{2} T_{0} \\
&+8 \mathrm{~d} \delta w_{0}-2 \mathrm{~d} \delta^{2} w_{0}-2 \alpha^{2}\left[2 w_{0}-2 m-\delta\left(1-c_{n}-m-T_{0}\right)\right] \\
&-\delta h_{e}\left[c_{n}(4+\delta)-\delta\left(1-m-T_{0}\right)+4\left(T_{0}+w_{0}-1\right)\right] \sigma \\
&-\delta \sigma^{2}\left[4 c_{r}-4 s+4 w_{0}+\delta\left(w_{0}-m-4\right)\right] \\
&-2 \alpha h_{e}\left[2 c_{r}+4 m+\delta\left(1-3 c_{n}-3 m-3 T_{0}\right)-2\left(s+w_{0}\right)\right] \\
& q_{r}^{T S^{*}}=+2 \alpha \sigma \delta\left(2-2 c_{n}-c_{r}+\delta+s-2 T_{0}-3 w_{0}\right) \\
&\left.\delta\left[d(4-\delta)^{2}-2(\alpha-2 \sigma)^{2}\right]-2(8-3 \delta) h_{e}^{2}-2 \delta^{2} h_{e} \sigma+8 \alpha h_{e}(2-\delta)\right]
\end{aligned}
$$

where $\delta\left[d(4-\delta)^{2}-2(\alpha-2 \sigma)^{2}\right] \quad-2(8-3 \delta) h_{e}^{2}$ $\left.-2 \delta^{2} h_{e} \sigma+8 \alpha h_{e}(2-\delta)\right]>0$.

\subsection{The Impact of Responsibility Transfer}

4.2.1. TA Scenario. Based on formulas (3)-(5), the partial derivative results can be obtained as follows

$$
\begin{aligned}
& \frac{\partial e^{T A^{*}}}{\partial h_{e}}=\frac{\tau(2+\delta \tau)\left\{d(2+\delta \tau)^{2}\left(K-T_{0}\right)+2 \sigma^{2}\left[K-T_{0}+\tau(2+\delta \tau)\left(w_{0}-m\right)\right]\right\}}{\left\{d(2+\delta \tau)^{2}-2 \sigma\left[h_{e} \tau(2+\delta \tau)+\sigma\right]\right\}^{2}}>0, \\
& \frac{\partial q_{n}^{T A^{*}}}{\partial h_{e}}=\frac{\tau\left\{d \sigma(2+\delta \tau)^{2}\left(K-T_{0}\right)+2 \sigma^{3}\left[K-T_{0}+\tau(2+\delta \tau)\left(w_{0}-m\right)\right]\right\}}{\left\{d(2+\delta \tau)^{2}-2 \sigma\left[h_{e} \tau(2+\delta \tau)+\sigma\right]\right\}^{2}}>0, \\
& \frac{\partial q_{r}^{T A^{*}}}{\partial h_{e}}=\frac{\tau^{2}\left\{d \sigma(2+\delta \tau)^{2}\left(K-T_{0}\right)+2 \sigma^{3}\left[K-T_{0}+\tau(2+\delta \tau)\left(w_{0}-m\right)\right]\right\}}{\left\{d(2+\delta \tau)^{2}-2 \sigma\left[h_{e} \tau(2+\delta \tau)+\sigma\right]\right\}^{2}}>0 .
\end{aligned}
$$

It can be seen that in the $T A$ scenario, $e^{T A^{*}}, q_{n}^{T A^{*}}, q_{r}^{T A^{*}}$ are increasing with respect to the transfer coefficient $h_{e}$. So, the larger the transfer coefficient $h_{e}$ is, the more beneficial it is to the ecodesign and manufacturing/remanufacturing activities at the supply chain level.

4.2.2. TS Scenario. The effects of $h_{e}$ on the optimal solutions $e^{T S^{*}}, q_{n}^{T S^{*}}, q_{r}^{T S^{*}}$ in the $T S$ scenario can be plotted as shown in Figure 3.

From Figure 3, we can observe the following:

(a) In the production stage, both the manufacturer's ecodesign effort and the production quantity of new products first increase and then decrease with respect to $h_{e}$ (Figures 3(a) and 3(b))

(b) In the remanufacturing stage, both the quantity of remanufactured products and the remanufacturing rate first decrease and then increase with respect to $h_{e}$ (Figures 3(c) and 3(d)) (c) There is a threshold of $h_{e}$ (Figure 3(e)), above which an increase in $h_{e}$ has a negative impact on the total quantity of new and remanufactured products

In conclusion, the manufacturer should comprehensively consider the impact of $h_{e}$ on itself, the remanufacturer, and the overall production activities, and carefully set the ecodesign responsibility transfer coefficient, which should stay beneath a certain threshold in the TS scenario.

\section{Comparative Analysis}

5.1. The Overall Impact of the Fund Policy. By comparing the optimal decision expressions (3)-(8) in Section 4 with the optimal decisions in Table 2 of Section 3, it is evident that when the responsibility transfer strategy is adopted by the manufacturer, the impact scope of $T_{0}, \sigma, s$ on the decisionmaking $e^{*}, q_{n}^{*}, q_{r}^{*}$ remains unchanged. However, when the partial derivatives of the optimal solution with respect to $T_{0}, \sigma, s$ are changed, the parameters involved are also changed. Take the partial derivative of $e^{B A^{*}}$ and $e^{T A^{*}}$ with respect to $T_{0}$ as an example.

$$
\frac{\partial e^{B A^{*}}}{\partial T_{0}}=\frac{-2 \sigma}{d(2+\delta \tau)^{2}-2 \sigma^{2}}>\frac{\partial e^{T A^{*}}}{\partial T_{0}}=\frac{-2 \sigma}{d(2+\delta \tau)^{2}-2 \sigma^{2}-2 \sigma h_{e} \tau(2+\delta \tau)}
$$




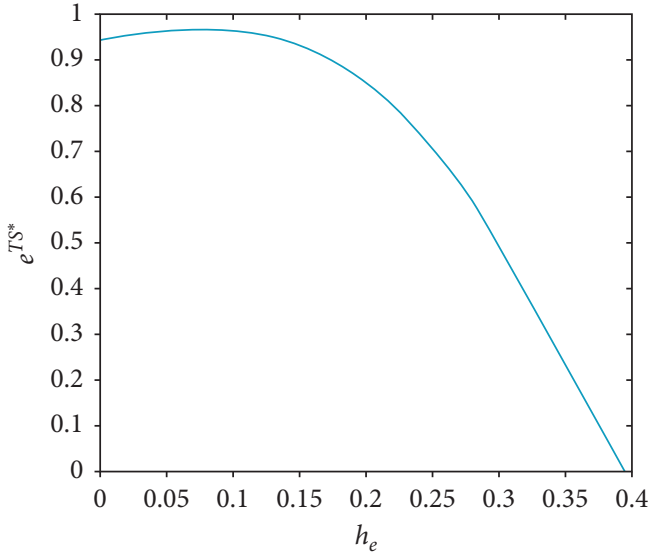

(a)

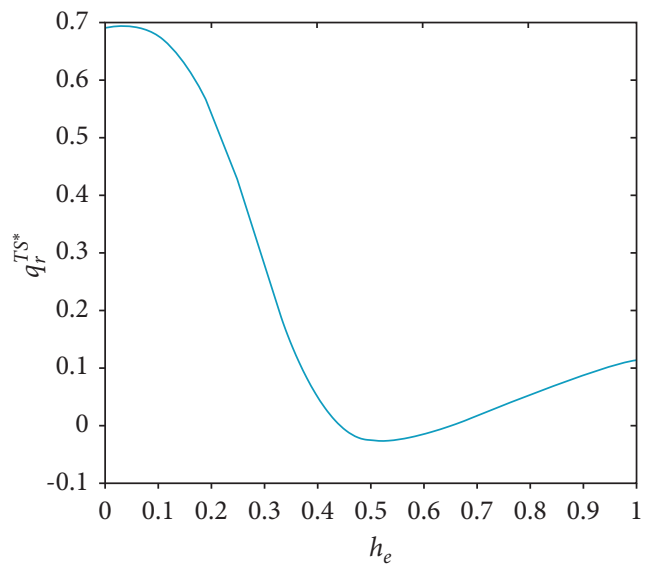

(c)

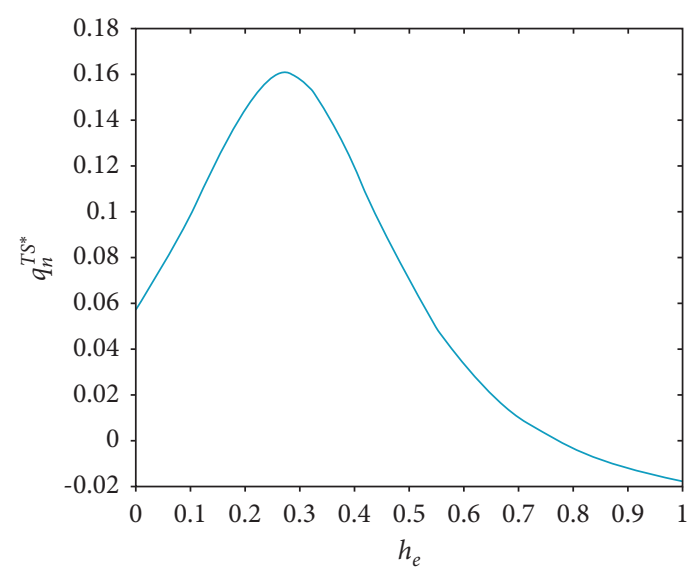

(b)

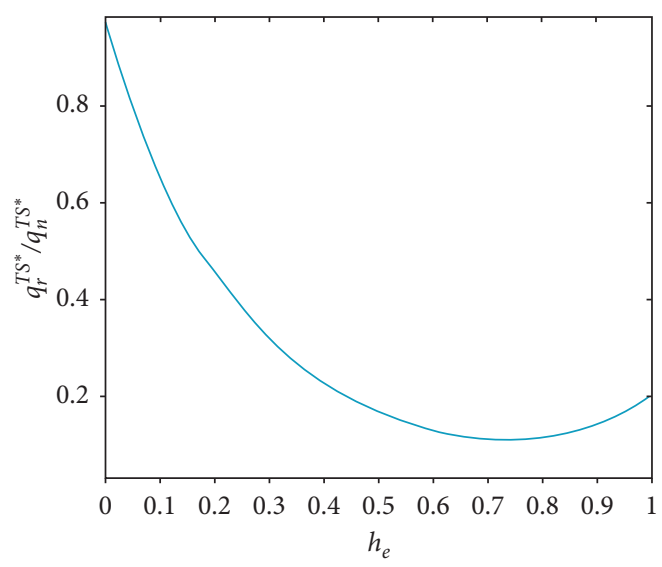

(d)

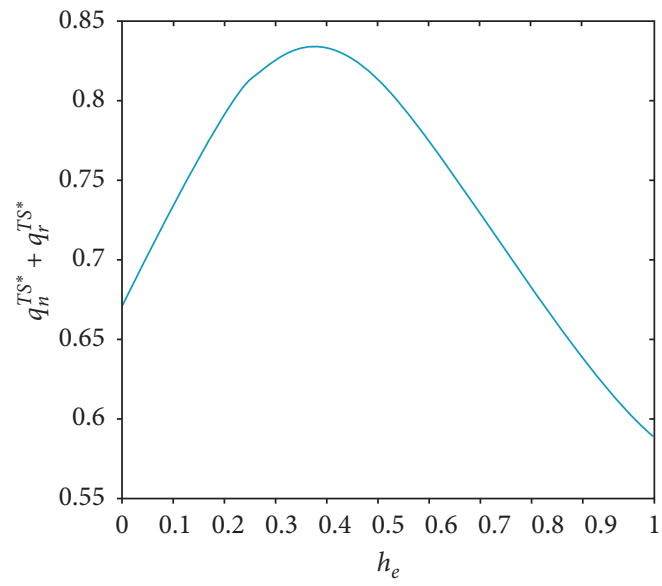

(e)

FIGURE 3: Effect of $h_{e}$ in the TS scenario. (a) Effect of $h_{e}$ on $e^{T S^{*}}$. (b) Effect of $h_{e}$ on $q_{n}^{T S^{*}}$. (c) Effect of $h_{e}$ on $q_{r}^{T S^{*}}$. (d) Effect of $h_{e}$ on $q_{r}^{T S^{*}} / q_{n}^{T S^{*}}$. (e) Effect of $h_{e}$ on $q_{n}^{T S^{*}}+q_{r}^{T S^{*}}$. 


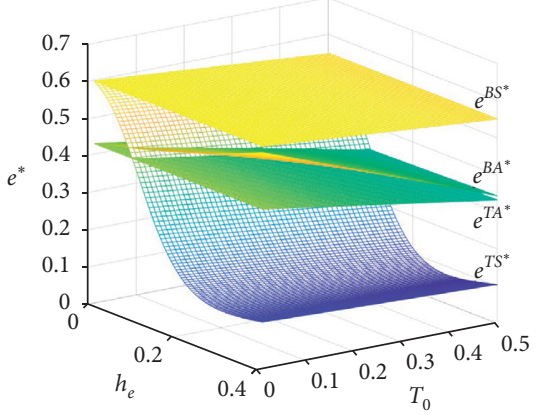

(a)

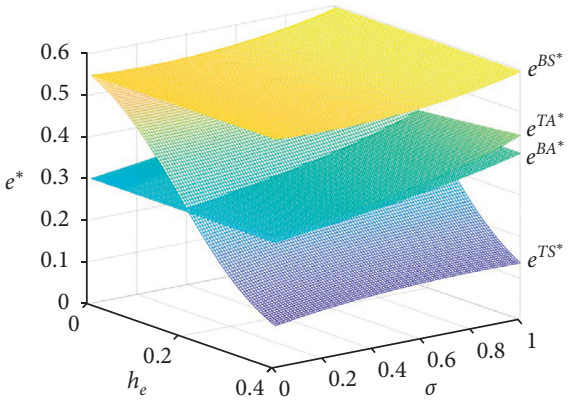

(b)

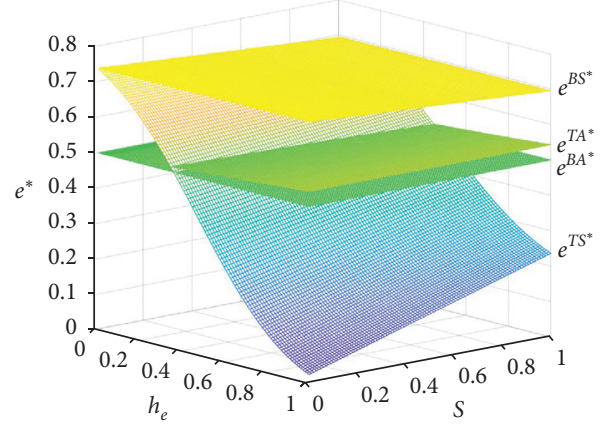

(c)

Figure 4: Effects of parameters $T_{0}, \sigma, s$, and $h_{e}$ on $e^{*}$. (a) Effects of $T_{0}$ and $h_{e}$ on $e^{*}$. (b) Effects of $\sigma$ and $h_{e}$ on $e^{*}$. (c) Effects of $s$ and $h_{e}$ on $e^{*}$.

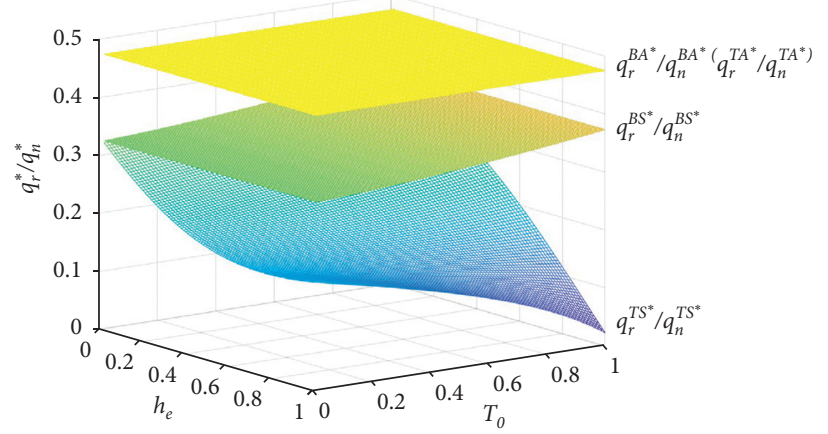

(a)

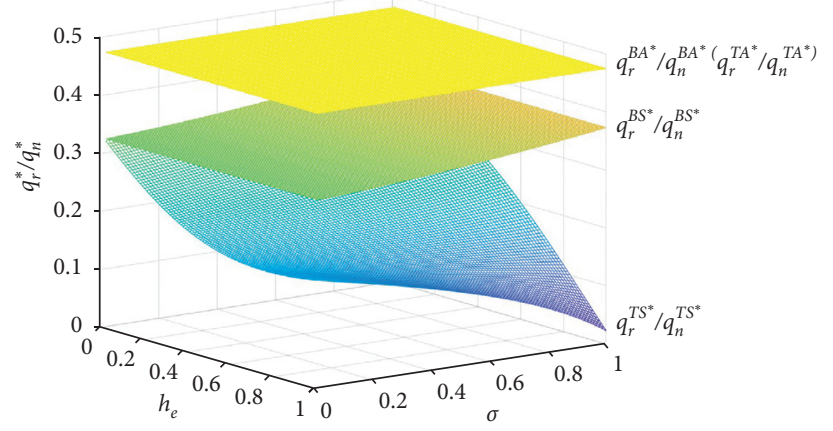

(b)

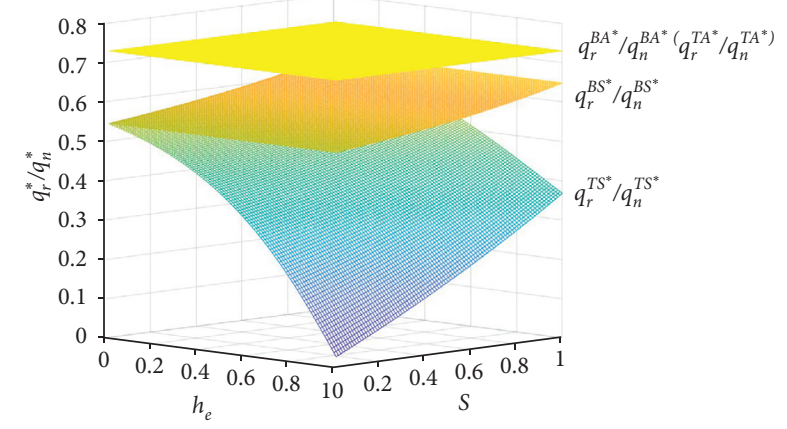

(c)

Figure 5: Effects of $T_{0}, \sigma$, and $h_{e}$ on $q_{r}^{*} / q_{n}^{*}$. (a) Effects of $T_{0}$ and $h_{e}$ on $q_{r}^{*} / q_{n}^{*}$. (b) Effects of $\sigma$ and $h_{e}$ on $q_{r}^{*} / q_{n}^{*}$. (c) Effects of $s$ and $h_{e}$ on $q_{r}^{*} / q_{n}^{*}$. 
It is evident that the manufacturer's production decision behavior is more sensitive to the $\operatorname{tax} T_{0}$ and parameters in the partial derivative also change when the responsibility transfer strategy is adopted by the manufacturer. Therefore, Conclusion 2 can be drawn.

Conclusion 2. When the manufacturer adopts an ecodesign responsibility transfer strategy, the impact scope of fund policy does not change. However, both the impact strength and the impact path of fund policy change when the manufacturer adopts the responsibility transfer strategy in a manufacturing-remanufacturing competition system.

5.2. Ecodesign Behavior. The impacts of the three dimensions of the fund policy $T_{0}, \sigma, s$, and transfer coefficient $h_{e}$, on the ecodesign effort of the manufacturer are plotted in Figure 4.

From Figure 4, we can observe the following:

(a) In the TS scenario, the transfer coefficient $h_{e}$ has a significant influence on the manufacturer's ecodesign behavior, and the manufacturer's ecodesign effort generally declines with the increase of the transfer coefficient $h_{e}$

(b) $e^{B S^{*}}>e^{T S^{*}}>e^{T A^{*}}>e^{B A^{*}}$ when the transfer coefficient $h_{e}$ is beneath a certain threshold; otherwise, $e^{B S^{*}}>e^{T A^{*}}>e^{B A^{*}}>e^{T S^{*}}$

Therefore, the manufacturer's ecodesign effort is the highest in the $B S$ scenario under the constraints of fund policy, while ecodesign effort is relatively low in the $B A$ scenario. The ecodesign transfer coefficient $h_{e}$ of the manufacturer should be beneath a certain threshold in the TS scenario to avoid having the responsibility transfer strategy negatively affect ecodesign.

5.3. Remanufacturing Rate. The impacts of the three dimensions of the fund policy $T_{0}, \sigma, s$, and transfer coefficient $h_{e}$ on the remanufacturing rate are plotted in Figure 5.

From Figure 5, we can observe that the remanufacturing rate has a complex and sensitive response to parameters $T_{0}, \sigma, s$ and transfer coefficient $h_{e}$. We can also observe that the remanufacturing rate decreases with the increase of the transfer coefficient $h_{e}$ in the TP scenario.

Therefore, the ecodesign transfer coefficient $h_{e}$ of the manufacturer should be beneath a certain threshold in the TS scenario to avoid having the responsibility transfer strategy negatively affect the remanufacturing rate.

\section{Conclusion}

The paper considers a manufacturing-remanufacturing competition system composed of a single manufacturer and a single remanufacturer under the constraints of fund policy. The government designs the fund policy, which mainly includes three dimensions, namely, tax, reduction, and subsidy. The manufacturer produces a key component and a new product in the market. The key component cannot be remanufactured and can only be sold by the manufacturer at a buyer-specific wholesale price or through a responsibility transfer strategy. The remanufacturer recycles old parts and purchases key components from the manufacturer for remanufacturing activities. The new product and remanufactured product are competitive substitutes in the market.

Based on game models and the obtained perfect equilibria, the main conclusions of this paper are as follows: (1) The impact scope of tax or reduction is larger than that of subsidy. The factors of tax, reduction, and subsidy affect all the decisions in both the $B S$ and $B A$ scenarios. However, the subsidy for encouraging remanufacturing is ineffective in the $B A$ scenario. (2) In the $B A$ scenario, the tax and the reduction have opposite effects on supply chain decisions, where the increase of tax will lead to the decline of ecodesign effort and the reduction of manufacturing and remanufacturing quantity. (3) In the BS scenario, the impact mechanism on decisions of the tax, reduction, and subsidy dimensions of fund policy changes complexly. In particular, the reduction dimension of fund policy may not only weaken ecodesign and remanufacturing at the supply chain level, but also lead to negative impacts from the tax and subsidy dimensions of fund policy at the policy level. (4) The responsibility transfer behavior of the manufacturer does not change the impact scope of the fund policy, but changes its impact strength and impact path. (5) The impact of the transfer coefficient on enterprises' decision-making varies with different remanufacturing scenarios. The higher the transfer coefficient, the higher the ecodesign effort will be, and the more the manufacturing and remanufacturing quantities will be in the TA scenario. However, the effect of the transfer coefficient on enterprises' decision-making is generally negative in the TS scenario.

Based on the above conclusions, the following guidelines are proposed to regulators and manufacturers in this paper: (1) The regulator needs flexibility in allocation of the tax, reduction, and subsidy factors of fund policy according to market conditions, considering the impact scope, strength, and path of fund subsidy, and the different remanufacturing strategies and manufacturer's ecodesign responsibility transfer behavior. (2) When the market environment is extremely favorable for remanufacturing and the remanufacturer decides to use all the collected returns for remanufacturing, the subsidy policy for encouraging recycling and remanufacturing is ineffective. The focus of fund policy design by the government should be the tax dimension and the reduction dimension. By reducing the tax or increasing tax reduction, the manufacturer can be encouraged to improve ecodesign efforts and strengthen the prevention of waste management at the production stage. (3) When the manufacturer uses some of the collected returns for remanufacturing, the impact mechanism of fund policy factors changes complexly. Thus, the government should integrate the design of the three dimensions, tax, reduction, and subsidy, of the fund policy to ensure a balanced guidance of fund policy on ecodesign behavior and remanufacturing behavior. In particular, the reduction dimension of fund policy must be set carefully; otherwise, it will not only weaken ecodesign and remanufacturing at the supply chain level, but will also lead to negative impacts from the tax and 
subsidy factors of fund policy on ecodesign and remanufacturing at the policy level. (4) In order to achieve better ecodesign and manufacturing/remanufacturing activities at the supply chain level, the manufacturer should adopt different ecodesign responsibility transfer strategies according to the remanufacturer's remanufacturing strategy. When the remanufacturer uses all collected returns for remanufacturing, the manufacturer can adopt the responsibility transfer strategy to achieve higher ecodesign and remanufacturing performance. On the contrary, when the remanufacturer uses some of the collected returns for remanufacturing, the manufacturer should keep the ecodesign transfer coefficient beneath a certain threshold and even forgo adopting a responsibility transfer strategy.

Finally, there are still some limitations in the research process of this paper. This paper only considers a single monopoly manufacturer in the manufacturing-remanufacturing system. It would be worthwhile to extend our study to the setting with competing manufacturers and examine how competition among manufacturers impacts the design of fund subsidies. In addition, there are various forms of responsibility transfer. Future studies can explore the effect of various responsibility transfer strategies in the manufacturing-remanufacturing system, including ecodesign responsibility transfer strategies, recycling, and remanufacturing responsibility transfer strategies.

\section{Appendix}

Proof. of Proposition 1. We solve the two-stage game by backward induction. First, $q_{n}, q_{r}$ are obtained and substituted back to $\pi_{m}, \pi_{r}$, and then $e$ can be obtained.

\section{Second Stage}

$$
\begin{aligned}
& \frac{\partial^{2} \pi_{m}}{\partial q_{n}^{2}}=-2<0, \\
& \frac{\partial^{2} \pi_{r}}{\partial q_{r}^{2}}=-2 \delta<0 .
\end{aligned}
$$

Therefore, the manufacturer's profit function $\pi_{m}$ is a concave function of new product quantity $q_{n}$. The remanufacturer's profit function $\pi_{r}$ is a concave function of remanufactured product quantity $q_{r}$.

Construct Lagrangian functions: $L_{r}=\pi_{r}-\lambda_{1}\left(q_{r}-\tau q_{n}\right)$ $-\lambda_{2}\left(-q_{r}\right),\left(\partial L_{r} / \partial q_{r}\right)=0$.

$$
\lambda_{1}\left(q_{r}-\tau q_{n}\right)=\lambda_{2} q_{r}=0, \quad 0 \leq q_{r} \leq \tau q_{n} .
$$

(a) $B A$ scenario: the remanufacturer uses all the collected returns for remanufacturing.

Let $\lambda_{1}>0, \lambda_{2}=0$, get $q_{r}=\tau q_{n}$, combine $\left(\partial L_{r} / \partial q_{r}\right)$ $=0, \lambda_{2}=0,\left(\partial \pi_{m} / \partial q_{n}\right)=0$.

$$
\begin{aligned}
& \text { Then, } \quad q_{n}^{B A}=\left(\left(\left(1-T_{0}-c_{n}-m+\sigma e\right) /(2+\delta \tau)\right),\right. \\
& q_{r}^{B A}=\left(\left(1-T_{0}-c_{n}-m+\sigma e\right) \tau /(2+\delta \tau)\right):
\end{aligned}
$$

$$
\begin{gathered}
2\left(\alpha e+s-w_{0}\right)+\delta\left[1+c_{n}+m+2 m \tau+2 c_{n} \tau+T_{0}\right. \\
\lambda_{1}=\frac{\left.+\tau\left(\delta+\alpha e+s+m+2 T_{0}-w_{0}-2\right)-e \sigma(1+2 \tau)\right]-c_{r}(2+\delta \tau)}{2+\delta \tau} .
\end{gathered}
$$

(b) BS scenario: the remanufacturer uses some of the collected returns for remanufacturing.

Let $\lambda_{1}=0, \lambda_{2}=0$, get $0<q_{r}<\tau q_{n}$, and combine $\left(\partial L_{r} / \partial q_{r}\right)=0,\left(\partial \pi_{m} / \partial q_{n}\right)=0$; then,

$$
\begin{aligned}
& q_{n}^{B S}=\frac{2-2 c_{n}+c_{r}-\delta-\alpha e-m-s-2 T_{0}+w_{0}+2 \sigma e}{4-\delta}, \\
& q_{r}^{B S}=\frac{2\left(\alpha e+s-w_{0}\right)-2 c_{r}+\delta\left(1+c_{n}+m+T_{0}-\sigma e\right)}{(4-\delta) \delta} .
\end{aligned}
$$

(c) $B N$ scenario: no remanufacturing.

Let $\lambda_{1}=0, \lambda_{2}>0$, get $q_{r}=0$, and combine $\left(\partial L_{r} / \partial q_{r}\right)$ $=0, \lambda_{1}=0,\left(\partial \pi_{m} / \partial q_{n}\right)=0 ; \quad$ then, $\quad q_{n}^{B N}=((1-c n-m$
$\left.\left.-T_{0}+\delta e\right) / 2\right), \quad q_{r}^{B N}=0, \quad \lambda_{2}=c_{r}-\alpha e \quad-s+w_{0}-(\delta(1+$ $\left.c_{n}+m+T_{0}-\sigma e\right) / 2$ ).

Since there is no remanufacturing behavior in the $B N$ scenario, which is not consistent with the main focus of this paper, it will not be discussed below.

\section{First Stage}

(a) BA scenario: the remanufacturer uses all the collected returns for remanufacturing.

$\frac{\partial^{2} \pi_{m}}{\partial^{2} e}=-d+\frac{2 \sigma^{2}}{(2+\delta \tau)^{2}}=\frac{2 \sigma^{2}-d(2+\delta \tau)^{2}}{(2+\delta \tau)^{2}}$.

Let $d(2+\delta \tau)^{2}-2 \sigma^{2}<0$; make $\left(\partial \pi_{m} / \partial e\right)=0$ 


$$
\begin{aligned}
& e^{B A^{*}}=\frac{\left\{2-2 c_{n}-m[2+\tau(2+\delta \tau)]-2 T_{0}+w_{0} \tau(2+\delta \tau)\right\} \sigma}{d(2+\delta \tau)^{2}-2 \sigma^{2}}, \\
& q_{n}^{B A^{*}}=\frac{d(2+\delta \tau)\left(1-c_{n}-m-T_{0}\right)+\left(w_{0}-m\right) \tau \sigma^{2}}{d(2+\delta \tau)^{2}-2 \sigma^{2}}, \\
& q_{r}^{B A^{*}}=\frac{\left[d(2+\delta \tau)\left(1-c_{n}-m-T_{0}\right)+\left(w_{0}-m\right) \tau \sigma^{2}\right] \tau}{d(2+\delta \tau)^{2}-2 \sigma^{2}} .
\end{aligned}
$$

(b) BS scenario: the remanufacturer uses some of the collected returns for remanufacturing.

$$
\frac{\partial^{2} \pi_{m}}{\partial^{2} e}=\frac{2(\alpha-2 \sigma)^{2}-d(4-\delta)^{2}}{(4-\delta)^{2}}
$$

Let $d(4-\delta)^{2}-2(\alpha-2 \sigma)^{2}>0$; make $\left(\partial \pi_{m} / \partial e\right)=0$ :

$$
\begin{aligned}
& e^{B S^{*}}=\frac{2 \delta(2 \sigma-\alpha)\left(2-c_{n}-m-\Delta-\delta-s-2 T_{0}\right)+\left(8 \alpha-4 \alpha \delta+\sigma \delta^{2}\right)\left(w_{0}-m\right)}{\delta\left[d(4-\delta)^{2}-2(\alpha-2 \sigma)^{2}\right]}, \\
& q_{n}^{B S^{*}}=\frac{d \delta(4-\delta)\left(2-c_{n}-m-\Delta-\delta-s-2 T_{0}\right)+[d \delta(4-\delta)-(\alpha-2 \sigma)(2 \alpha-\delta \sigma)]\left(w_{0}-m\right)}{\delta\left[d(4-\delta)^{2}-2(\alpha-2 \sigma)^{2}\right]} \\
& q_{r}^{B S^{*}}=\frac{\left\{\begin{array}{c}
d \delta(4-\delta)\left[\delta\left(1+c_{n}+m+T_{0}\right)-2 c_{r}-2\left(m-s+w_{0}\right)\right] \\
+2 \alpha \sigma \delta\left(2-c_{n}-m-\Delta-2 m+s-2 T_{0}-3 m\right) \\
+\delta \sigma^{2}\left[4 c_{r}-4(\delta-m+s)+(4+\delta) w_{0}\right]-2 \alpha^{2}\left[\delta\left(1-c_{n}-m-T_{0}\right)-2 w_{0}\right]
\end{array}\right]}{\delta^{2}\left[d(4-\delta)^{2}-2(\alpha-2 \sigma)^{2}\right]} .
\end{aligned}
$$

Proof. of Proposition 2

$$
\begin{aligned}
& \frac{\partial e^{B A^{*}}}{\partial T_{0}}=\frac{-2 \sigma}{d(2+\delta \tau)^{2}-2 \sigma^{2}}<0, \\
& \frac{\partial q_{n}^{B A^{*}}}{\partial T_{0}}=\frac{-d(2+\delta \tau)}{d(2+\delta \tau)^{2}-2 \sigma^{2}}<0, \\
& \frac{\partial q_{r}^{B A^{*}}}{\partial T_{0}}=\frac{-d \tau(2+\delta \tau)}{d(2+\delta \tau)^{2}-2 \sigma^{2}}<0, \\
& \frac{\partial e^{B A^{*}}}{\partial \sigma}=\frac{\left[2\left(K-T_{0}\right)+\tau(2+\delta \tau)\left(w_{0}-m\right)\right]\left[d(2+\delta \tau)^{2}+2 \sigma^{2}\right]}{\left[d(2+\delta \tau)^{2}-2 \sigma^{2}\right]^{2}}>0, \\
& \frac{\partial q_{n}^{B A^{*}}}{\partial \sigma}=\frac{2 d(2+\delta \tau)\left[2\left(K-T_{0}\right)+\tau(2+\delta \tau)\left(w_{0}-m\right)\right] \sigma}{\left[d(2+\delta \tau)^{2}-2 \sigma^{2}\right]^{2}}>0, \\
& \frac{\partial q_{r}^{B A^{*}}}{\partial \sigma}=\frac{2 d \tau(2+\delta \tau)\left[2\left(K-T_{0}\right)+\tau(2+\delta \tau)\left(w_{0}-m\right)\right] \sigma}{\left[d(2+\delta \tau)^{2}-2 \sigma^{2}\right]^{2}}>0 .
\end{aligned}
$$

$e^{B A^{*}}, q_{r}^{B A^{*}}, q_{n}^{B A^{*}}$ expressions have no $s$, so they are not affected by $s$. (b) BS scenario: the remanufacturer uses some of the collected returns for remanufacturing $\left(\partial e^{B S^{*}} / \partial T_{0}\right)$ 
$=\left(4(\alpha-2 \sigma) /\left(d(4-\delta)^{2}-2(\alpha-2 \sigma)^{2}\right)\right)$,

$\left(\partial e^{B S^{*}} / \partial T_{0}\right)>0$ when $\alpha-2 \sigma>0$, and vice versa.

$\frac{\partial q_{n}^{B S^{*}}}{\partial T_{0}}=\frac{-2 d(4-\delta)}{d(4-\delta)^{2}-2(\alpha-2 \sigma)^{2}}<0$ $\left(\partial q_{r}^{B S^{*}} / \partial T_{0}\right)=\left(2 \alpha(\alpha-2 \sigma)+d \delta(4-\delta) / \delta\left[d(4-\delta)^{2}-\right.\right.$

$\left.\left.2(\alpha-2 \sigma)^{2}\right]\right)>0\left(\partial q_{r}^{B S^{*}} / \partial T_{0}\right)>0$ when $\alpha-2 \sigma>0$, otherwise uncertain.

$$
\begin{aligned}
& 2 \alpha^{2}\left\{4 \delta\left[2\left(K-T_{0}\right)+c_{r}-3 m-s+4 w_{0}\right]-32\left(w_{0}-m\right)-\delta^{2}\left(4+w_{0}-m\right)\right\} \\
& -32 \alpha \sigma\left\{\delta\left[2\left(K-T_{0}\right)+c_{r}-\delta-m-s+2 w_{0}\right]-4\left(w_{0}-m\right)\right\} \\
& \frac{\partial e^{B S^{*}}}{\partial \sigma}=\frac{-\delta\left[4 s+4 \delta-4 m-4 c_{r}-\left(w_{0}-m\right) \delta-8\left(K-T_{0}\right)\right]\left[d(4-\delta)^{2}+8 \sigma^{2}\right]}{\delta\left[d(4-\delta)^{2}-2(\alpha-2 \sigma)^{2}\right]^{2}}, \\
& \frac{\partial q_{n}^{B S^{*}}}{\partial \sigma}=\frac{(4-\delta)\left\{\begin{array}{c}
2 \alpha^{3}\left(w_{0}-m\right)+\alpha d\left\{16\left(w_{0}-m\right)+\delta\left[16\left(K-T_{0}\right)+8\left(w_{0}-m\right)+8 c_{r}-8 s-8 \delta-\delta w_{0}\right]\right\} \\
+4 d \delta \sigma\left[8 c_{n}+4 c_{r}+4\left(2-m-s-2 T_{0}\right)+\delta\left(4+w_{0}-m\right)\right]-8 \alpha^{2}\left(w_{0}-m\right) \sigma+8 \alpha\left(w_{0}-m\right) \sigma^{2}
\end{array}\right\}}{\delta\left[d(4-\delta)^{2}-2(\alpha-2 \sigma)^{2}\right]^{2}},
\end{aligned}
$$

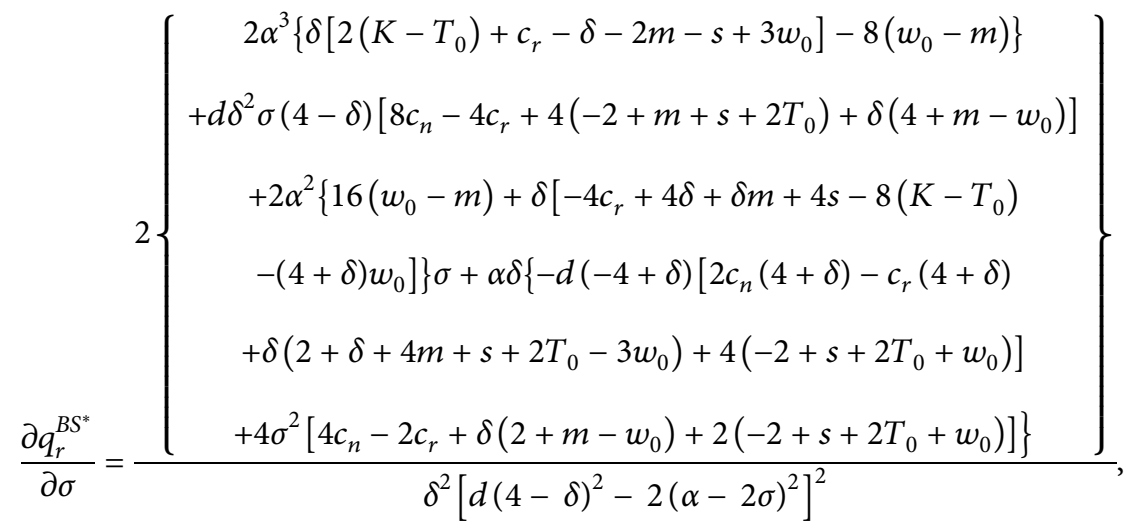

$\left(\partial e^{B S^{*}} / \partial s\right)=\left(2(\alpha-2 \sigma) /\left[d(4-\delta)^{2}-2(\alpha-2 \sigma)^{2}\right]\right)$,

$\left(\partial e^{B S^{*}} / \partial s\right)>0$ when $\alpha-2 \sigma>0$, otherwise $\left(\partial e^{B S^{*}} / \partial s\right) \leq 0$

$$
\frac{\partial q_{n}^{B S^{*}}}{\partial s}=\frac{-d(4-\delta)}{d(4-\delta)^{2}-2(\alpha-2 \sigma)^{2}}<0
$$

$\left(\partial q_{r}^{B S^{*}} / \partial s\right)=\left(2+2 \sigma \delta(\alpha-2 \sigma) / \delta^{2}\left[d(4-\delta)^{2}-2(\alpha-2 \sigma)^{2}\right]\right)$ $>0$, $\left(\partial q_{r}^{B S^{*}} / \partial T_{0}\right)>0$ when $\alpha-2 \sigma>0$, otherwise uncertain.

\section{Data Availability}

The model of this paper is the authors' innovative construction on the basis of referring to the relevant literature. The data used are computer simulation data, and the relevant data have been indicated in the paper. According to the appendix, this paper has two propositions and two stages. Each stage has different calculation methods and formulas.

\section{Conflicts of Interest}

The authors declare that they have no conflicts of interest.

\section{Acknowledgments}

This study was supported by the National Natural Science Foundation of China (72074078, 71473085, and 71871117), the Shanghai Natural Science Foundation (20ZR1413300), and the Fundamental Research Funds for Central Universities of China.

\section{References}

[1] OECD, Extended Producer Responsibility A Guidance Manual For Governments, OECD, Paris, France, 2001.

[2] I.-H. Hong and J.-S. Ke, "Determining advanced recycling fees and subsidies in "E-scrap" reverse supply chains," Journal of Environmental Management, vol. 92, no. 6, pp. 1495-1502, 2011.

[3] H.-S. Shih, "Policy analysis on recycling fund management for E-waste in Taiwan under uncertainty," Journal of Cleaner Production, vol. 143, no. 2, pp. 345-355, 2017.

[4] J. Cao, B. Lu, Y. Chen et al., "Extended producer responsibility system in China improves e-waste recycling: government 
policies, enterprise, and public awareness," Renewable and Sustainable Energy Reviews, vol. 62, no. 4, pp. 882-894, 2016.

[5] G. Liu, Y. Xu, T. T. Tian, T. Wang, and Y. Liu, "The impacts of China's fund policy on waste electrical and electronic equipment utilization," Journal of Cleaner Production, vol. 251, no. 4, pp. 582-587, 2020.

[6] E. Plambeck and Q. Wang, "Effects of e-waste regulation on new product introduction," Management Science, vol. 55, no. 3, pp. 333-347, 2009.

[7] A. Atasu, L. N. Van Wassenhove, and M. Sarvary, "Efficient take-back legislation," Production and Operations Management, vol. 18, no. 3, pp. 243-258, 2009.

[8] ISO, 14006:2020. Environmental Management SystemsGuidelines for Incorporating Eco-Design, ISO, Geneva, Switzerland, 2011.

[9] A. Atasu and G. C. Souza, "How does product recovery affect quality choice?" Production and Operations Management vol. 22, no. 4, pp. 242-261, 2013.

[10] J. Cheng, B. Li, B. Gong, M. Cheng, and L. Xu, "The optimal power structure of environmental protection responsibilities transfer in remanufacturing supply chain," Journal of Cleaner Production, vol. 153, no. 2, pp. 558-569, 2017.

[11] B. W. Jacobs and R. Subramanian, "Sharing responsibility for product recovery across the supply chain," Production and Operations Management, vol. 21, no. 1, pp. 85-100, 2012.

[12] A. Örsdemir, E. Kemahlığlu-Ziya, and A. K. Parlaktürk, "Competitive quality choice and remanufacturing," Production and Operations Management, vol. 23, no. 1, pp. 48-64, 2014.

[13] P. He, Y. He, and $\mathrm{H} . \mathrm{Xu}$, "Product variety and recovery strategies for a manufacturer in a personalised and sustainable consumption era," International Journal of Production Research, vol. 28, 2021.

[14] P. He, Y. He, and H. Xu, "Channel structure and pricing in a dual-channel closed-loop supply chain with government subsidy," International Journal of Production Economics, vol. 213, pp. 108-123, 2019.

[15] P. Kautto and M. Melanen, "How does industry respond to waste policy instruments-Finnish experiences," Journal of Cleaner Production, vol. 12, no. 1, pp. 1-11, 2004.

[16] H. Wang, Y. Gu, L. Li, T. Liu, Y. Wu, and T. Zuo, "Operating models and development trends in the extended producer responsibility system for waste electrical and electronic equipment," Resources, Conservation and Recycling, vol. 127, no. 9, pp. 159-167, 2017.

[17] Y. J. Li, S. Y. Niu, X. K. Zhao, and W. Wang, "Effect of EPR coefficient policy on the production decision in precious metal accessory recycling," International Journal of Production Research, vol. 74, no. 3, pp. 1129-1146, 2017.

[18] M. Pazoki, G. Zaccour, and Georges, "A mechanism to promote product recovery and environmental performance," European Journal of Operational Research, vol. 274, no. 2, pp. 601-614, 2019.

[19] G. Cao, Z. Dong, and Z. Zhang, "Research on threshold effect of environmental regulation and green total factor productivity," EDP Sciences, vol. 118, p. 3002, 2018.

[20] Q. Guo, E. Wang, Y. Nie, and J. Shen, "Profit or environment? a system dynamic model analysis of waste electrical and electronic equipment management system in China," Journal of Cleaner Production, vol. 194, no. 5, pp. 34-42, 2018.

[21] X. Chang, J. Wu, T. Li, and T.-J. Fan, "The joint tax-subsidy mechanism incorporating extended producer responsibility in a manufacturing-recycling system," Journal of Cleaner Production, vol. 210, no. 10, pp. 821-836, 2019.
[22] X. Chen, X. Wang, and Y. Xia, "Production coopetition strategies for competing manufacturers that produce partially substitutable products," Production and Operations Management, vol. 28, no. 6, pp. 1446-1464, 2019.

[23] Z. Hong and X. Guo, "Green product supply chain contracts considering environmental responsibilities," Omega, vol. 83, no. 3, pp. 155-166, 2019.

[24] M. Pazoki and H. Samarghandi, "Take-back regulation: remanufacturing or eco-design?" International Journal of Production Economics vol. 227, no. 1, Article ID 107674, 2020.

[25] Z. Wang, Q. Wang, B. Chen, and Y. Wang, "Evolutionary game analysis on behavioral strategies of multiple stakeholders in E-waste recycling industry," Resources, Conservation and Recycling, vol. 155, Article ID 104618, 2020.

[26] X. M. Zhang, J. Cao, X. H. Chen, YC. Gao, XP. Zhang, and S. Kumar, "Overview of remanufacturing industry in China: government policies, enterprise, and public awareness," Journal of Cleaner Production, vol. 242, no. 1, pp. 10-16, 2020.

[27] X. M. Zhang, Q. W. Li, Z. Liu, and C. T. Chang, "Optimal pricing and remanufacturing mode in a closed-loop supply chain of WEEE under government fund policy," Journal of Computers \& Industrial Engineering, vol. 151, pp. 1-17, Article ID 106951, 2021.

[28] Z. Liu, K. W. Li, J. Tang, B. Gong, and J. Huang, "Optimal operations of a closed-loop supply chain under a dual regulation," International Journal of Production Economics, vol. 233, Article ID 107991, 2021.

[29] P. Calcott and M. Walls, "Waste, recycling, and "Design for Environment": roles for markets and policy instruments," Resource and Energy Economics, vol. 27, no. 4, pp. 287-305, 2005.

[30] W. Zhu and Y. He, "Green product design in supply chains under competition," European Journal of Operational Research, vol. 258, no. 1, pp. 165-180, 2017.

[31] F. Zand, S. Yaghoubi, and S. J. Sadjadi, "Impacts of government direct limitation on pricing, greening activities and recycling management in an online to offline closed loop supply chain," Journal of Cleaner Production, vol. 215, no. 1, pp. 1327-1340, 2019.

[32] X. Zheng, K. Govindan, and Q. Deng, "Effects of design for the environment on firms' production and remanufacturing strategies," International Journal of Production Economics, vol. 213, pp. 217-228, 2019.

[33] R. Subramanian, M. E. Ferguson, and L. B. Toktay, "Remanufacturing and the component commonality decision," Production and Operations Management, vol. 22, no. 1, pp. 36-53, 2013.

[34] K. Mathiyazhagan, A. Diabat, A. Al-Refaie, and L. Xu, "Application of analytical hierarchy process to evaluate pressures to implement green supply chain management," Journal of Cleaner Production, vol. 117, pp. 229-236, 2015.

[35] C. K. Chen and M. A. Ulya, "Analyses of the reward-penalty mechanism in green closed-loop supply chains with product remanufacturing," International Journal of Production Economics, vol. 210, pp. 211-223, 2019.

[36] X. L. Wu and Y. Zhou, "Buyer-specific versus uniform pricing in a closed-loop supply chain with third-party remanufacturing," European Journal of Operational Research, vol. 273, no. 2, pp. 548-560, 2018.

[37] M. Reimann, Y. Xiong, and Y. Zhou, "Managing a closed-loop supply chain with process innovation for remanufacturing," European Journal of Operational Research, vol. 276, no. 2, pp. 510-518, 2019. 